\title{
De cómo la prensa del odio incitó el golpe de estado contra Chávez El poder mediático en Venezuela
}

\author{
MAURICE Lemoine \\ Versión: Lais Alvarenga, a partir de \\ la traducción inglesa de Julie Stoker
}

Nunca antes en la bistoria de Latinoamérica los medios de comunicación habian estado involucrados tan directamente en un golpe de estado. La "prensa del odio" de Venezuela -que controla el 95\% de los medios que salen al aire, y ejerce un virtual monopolio sobre la prensa escrita- ba desempeñado un papel sobresaliente en el intento fallido por derrocar al presidente Hugo Chavez en abril recién pasado. A pesar que las tensiones en el pais sudamericano pueden deslizarse fácilmente a una guerra civil, los medios de comunicación siguen incitando directamente a que los elementos disidentes derroquen a un mandatario democráticamente electo, inclusive, haciendo uso de la fuerza.

"Tenemos un arma mortífera: la prensa. $Y$ ahora que yo tengo la oportunidad, déjenme agradecerles”. En Caracas, el 11 de abril de 2002, a tan sólo a unas pocas horas después del efímero derrocamiento del presidente de Venezuela, Hugo Chávez, el Vicealmirante Víctor Ramírez Pérez felicitó con estas palabras a la periodista Ibéyiste

De cómo lo prenso del odio incitó el golpe de estado contro Chávez 
Pacheco en una transmisión en vivo difundida por la cadena televisiva Venevisión. Veinte minutos antes, cuando Pacheco había empezado a entrevistar a un grupo de oficiales rebeldes, la periodista no pudo resistirse a admitir, de manera cómplice, que ella tenía, desde hace mucho, una especial relación con ellos.

Entretanto, en una entrevista en vivo desde Madrid, otra periodista, Patricia Poleo, también parecía estar bien informada acerca del probable desarrollo ulterior de los "eventos espontáneos". Poleo anunció en la cadena española TVE: "Yo creo que el próximo presidente será Pedro Carmona". Chávez, refugiado en el palacio presidencial, todavía se resistía a darse por vencido.

Después de que Chávez llegara al poder en 1998, los cinco principales canales privados - Venevisión, Radio Caracas Televisión (RCTV), Globovisión y CMT - y nueve de los diez principales periódicos nacionales, incluyendo El Universal, Tal Cual, El Impulso, El Nuevo País y El Mundo, habían asumido el papel de los partidos políticos tradicionales, los cuales se vieron perjudicados por las victorias electorales del nuevo presidente. Su monopolio informativo los había colocado en una posición ventajosa. Le dieron apoyo a la oposición, dándole una escasa cobertura a las posiciones del gobierno y cuidándose de no mencionar jamás la amplia mayoría que apoyaba a éste, pese a que esa mayoría se vio confirmada en las urnas electorales. Estos medios siempre han descrito a los barrios donde vive la clase trabajadora como una zona roja habitada por peligrosos grupos de gente ignorante y de delincuente. Sin duda, al no considerarlos fotogénicos, ignoraron a los líderes de la clase obrera y a sus organizaciones.

Sus investigaciones, entrevistas y comentarios persiguen a una el mismo objetivo: minar la legitimidad del gobierno y socavar el apoyo popular del presidente. "En términos estéticos, este gobierno revolucionario es una sentina": tal fue la delicada frase que uso el periódico vespertino Tal Cual. Su editor, Teodoro Petkoff, es un entusiasta opositor de Chávez. Petkoff es un ex guerrillero marxista, quien se convirtió en un ministro neoliberal y favorable a las privatizaciones, en el gobierno derechista del presidente Rafael Caldera. El gobierno de Chávez no está, evidentemente, por encima de la crítica. Comete errores, y su personal civil y militar está manchado por la corrupción. Pero ese gobierno fue elegido democráticamente y todavía tiene el 
apoyo de la mayoría. Eso puede reafirmarse con los éxitos conseguidos tanto nacional como internacionalmente.

Cuando se trata de desacreditar a Chávez, todo vale. Hubo un escándalo en Caracas en marzo, cuando se puso en circulación una entrevista apócrifa con Ignacio Ramonet, director de Le Monde Diplomatique. En declararaciones supuestamente hechas a Emiliano Payares Guzmán, un investigador mexicano de la universidad de Princeton, Ramonet habría dicho: "Chávez carece de un bagaje intelectual respetable, y eso explica por qué su barco está siempre a la deriva. Cuando ganó las elecciones, me parecía que tenía algo especial. Pero ganó el populismo, como sucede frecuentemente en tales casos. He visto vídeos en los que aparece cantando boleros mientras plantea su programa económico, si es que acaso tiene alguno. Creo que estos hechos ciertos y verificables son elocuentes. No necesito dar mi opinión sobre alguien así".

Venezuela Analítical colocó inmediatamente las "declaraciones" en Internet, sin cerciorarse de su autenticidad, y de ahí se convirtió en noticia de primera plana en El Nacional. El periódico disfrutó darle credibilidad a la idea de que Chávez estaba aislado internacionalmente, y no hizo intento alguno para verificar la autenticidad del texto con el supuesto entrevistado. Cuando Ramonet negó haber dado las declaraciones, El Nacional se puso en contra del bromista² y, más embozadamente, sin disculparse tan siquiera, en contra de Ramonet.

La "información" publicada lindaba con lo surrealista. Por cjemplo, cosas como "fuentes de los servicios de inteligencia han develado acuerdos con elementos vinculados al Hezbollah en la isla venezolana de Margarita, bajo control de la embajada iraní. Ustedes recordarán que cuando Chávez estaba en campaña, un tal Moukhdah se mostraba extremadamente generoso. Esa deuda tenía que pagarse, y ahora Irán convertirá a Venezuela en su base de operaciones, a cambio de entrenar venezolanos en organizaciones iraníes para la defensa de la Revolución Islámica. El terrorismo está entre nosotros ${ }^{3}$.

El 21 de marzo, El Nacional publicó el siguiente encabezado: "Hugo Chávez admite ser la cabeza de una red criminal". Al siguiente día, Tal Cual declaró que "ni el coleto le va a ser suficiente [a Chávez] para restregar el vómito nauseabundo que han derramado sus palabras encolerizadas con las que pretende amedrentar al país"t. El presidente

De cómo la prensa del odio incitó el golpe de estado contro Chóvez 
fue insultado y se le comparó con Idi Amin, Mussolini o Hitler, fue tildado de fascista, dictador y tirano, y sometido a una avalancha de ataques. En cualquier otro país, ese tipo de acciones hubiera merecido una demanda por libelo. Como "un ataque irrespetuoso", lo catalogó el Ministro de Comercio, Adina Bastidas. "Me acusan de financiar las bombas que estallan en las calles. Y no puedo defenderme. iSi los atacas, ellos se quejan con los Estados Unidos!".

Chávez respondió a este bombardeo mediático, usando a veces lenguaje fuerte, especialmente durante su programa semanal de radio iAló, presidente!, en el único canal controlado por el Estado. Pero su régimen de ninguna manera evoca a una dictadura, y sus diatribas nunca han estado acompañadas de medidas para controlar la información. Desde que Chávez tomó posesión de su cargo, ningún periodista ha sido encarcelado y el gobierno no ha clausurado ningún medio de comunicación. Aún así, se ha visto acusado de "no acatar la libertad de información" y de "atacar a los comunicadores sociales".

\section{1. "Digan la verdad"}

El 7 de enero, un grupo de partidarios del presidente rodearon las oficinas de El Nacional coreando consignas hostiles. A los gritos de "iDigan la verdad!", arrojaron objetos al edificio. La cantidad de ataques contra los periodistas está aumentando, según Carlos Correa, coordinador general de Provea ${ }^{5}$, una organización defensora de los derechos humanos. Los comunicadores también se han visto convertidos en delincuentes "Aunque no ha habido muertes, la situación es seria. Desde que los jefes de los medios decidieron oponerse políticamente a Chávez, ya no es posible discutir razonablemente sobre los problemas del país. Pero decir que no hay libertad de expresión es escandaloso".

"Lees los periódicos, ves las noticias en la televisión y tienes la impresión de que el país está atenazado por el conflicto", dice consternado el sacerdote jesuita Francisco José Virtuoso. "Naturalmente, ello crea mayor tensión". Las mayorías populares está contraatacando en esta guerra de la cual es el blanco y que no están preparados para tolerar a periodistas que creen estar por encima de la ley o del control antidemocrático de la información. 
Los incidentes aumentan. La agencia oficial Venpres, se refiere a tres personalidades de los medios como "narcoperiodistas". Los periodistas en cuestión - Ibéyise Pacheco, editora de Asi es la noticia, miembro del grupo de El Nacional-, Patricia Poleo y el presentador de televisión José Domingo Blanco, de Globovisión- decidieron capitalizar las acusaciones. Después de condenar su "persecución" frente a las cámaras que estaban en la embajada estadounidense, se fucron a Washington, donde tuvieron un heroico recibimiento. El artículo de Venpres, firmado por un tal J. Valeverde ${ }^{6}$, fue repudiado por el presidente Chávez y condenado por el Ministro de Defensa, José Vicente Rangel; condujo a la censura y a la renuncia del director de Venpres, Óscar Navas. Pero ello no frenó la campaña, desplegada tanto en Venezuela como en el exterior, contra un gobierno acusado de "amordazar a los medios".

La prensa se mostró proclive a recurrir a la "profecía que se cumple por sí misma", tanto en relación con el gobierno como con el gobierno mismo. Al protestar sobre las infracciones a la libertad, sin estar bajo amenaza alguna, y recurriendo a las mentiras y a la manipulación, los medios provocaron una reacción, incitando a veces a sus víctimas a actuar erradamente. Estos desaciertos se hicieron ver como la causa (y no como la consecuencia) de la desafortunada relación entre el gobierno y una parte significativa de la población.

Debemos condenar los ataques perpetrados por los partidarios del presidente en contra de instalaciones televisivas o en contra de los periodistas. Pero, ¿cómo pueden estas personas tolerar que siempre se refieran a ellas como "talibanes", o como "villanos"? Debemos protestar cuando a los periodistas -incluso aquellos que son furibundos y están completamente identificados con la oligarquía - se les tacha de "narcoperiodistas". Pero estos mismos periodistas se han encargado de bombardear al presidente con acusaciones falsas y lo han retratado como el cómplice de las "narcoguerrillas" colombianas.

Conducidos por hombres influyentes y destacados periodistas, los medios de comunicación están poniéndose al servicio de otros jugadores en el proceso de desestabilización: La asociación patronal de Pedro Carmona (Fedecámaras), a Confederación de Trabajadores Venezolanas que domina Carlos Ortega, militares disidentes, tecnócratas de la compañía nacional de petróleo (PDVSA) y algunos funcionarios esta- 
dounidenses discretos?. Unidos en el Bloque de Prensa Venezolana (BPV), los medios de comunicación se pusieron en evidencia cuando se sumaron a la primera huelga general convocada para el 10 de diciembre de 2001.

\section{Alarmistas}

Las opiniones "libres" publicadas en los medios impresos - "Tiempo para cambiar de gobierno", o "Tiempo para derrocar a este gobierno" - se vieron reforzadas por la sospechosa manipulación de los medios radiales. El 5 de abril, dos presentadores de televisión ofrecieron sus comentarios personales sobre una huelga en las estaciones petroleras, las cuales estaban vinculadas al conflicto con PDVSA: "¿Recuerda usted que hay que llenar el tanque? Apúrese, porque mañana no habrá ni una sola gota de petróleo en el país". Al alentar a los conductores a apresurarse a comprar gasolina, provocaron un caos innecesario, aunque la huelga era tan sólo parcial y las gasolineras todavía estaban siendo abastecidas.

El 7 de abril, Ortega y Carmona anunciaron que esa no era una huelga general. El editor de El Nacional, Miguel Enrique Otero, se puso hombro a hombro con ellos y habló en nombre de la prensa: "Todos estamos involucrados en esta lucha en defensa del derecho a la información". Dos días más tarde, el BPV, el cual acababa de recibir la visita del embajador estadounidense, Charles Shapiro, decidió respaldar la huelga. A partir de entonces, las compañías televisivas transmitían en vivo desde las oficinas de PDVSA-Chuao, el punto de concentración designado para las manifestaciones opositoras.

"A tomar las calles", bramó El Nacional el 10 de abril (en un editorial sin firma). "iNi un paso atrás!"”, respondían las vallas publicitarias de Globovisión. En otra transmisión televisiva se decía: "Venezolanos: Tómense las calles el martes 11 de abril a las diez de la mañana. Traigan sus banderas. Por la libertad y la democracia, Venezuela no se rendirá. Nadic nos derrotará". El llamado a derrocar al jefe de estado se hizo tan obvio, que el gobierno aplicó el Artículo 192 de la Ley de Telecomunicaciones. Más de treinta veces - en todas las televisoras y estaciones de radio-, el gobierno hizo la requisición de espacios de 15 a 20 minutos en el aire para transmitir sus puntos de vista-. Pero

\section{2}

Realidad 90, 2002 
las cadenas de televisión dividieron la pantalla en dos y continuaron incitando a la rebelión.

El 11 de abril, las conferencias de prensa convocadas tanto por civiles como por militares para exigir la renuncia del presidente marcaron la siguiente fase. En RCTV, Ortega llamó a la oposición a marchar hacia el palacio presidencial de Miraflores. Cerca de las 4 de la tarde, cuando era obvia la escalada de la conspiración, las autoridades dieron la orden de bloquear las frecuencias utilizadas por canales privados. Globovisión, CMT y Televen se fueron del aire por unos breves momentos, antes de reanudar las transmisiones valiéndose del satélite o del cable. Todas las pantallas recibieron imágenes editadas para mostrar a contramanifestantes armados, abriendo fuego sobre "la multitud de manifestantes pacíficos". Como resultado de lo anterior, los Círculos Bolivarianos, la organización social de los partidarios de Chávez, fueron acusados de causar muertes y lesiones ${ }^{10}$.

Los conspiradores, incluyendo a Carmona, se reunieron en las oficinas de Venevisión. Ahí estuvieron hasta las dos de la madrugada, para preparar la "próxima etapa", junto a Rafael Poleo (dueño de El Nuevo País) y Gustavo Cisneros, una figura clave en el golpe. Cisneros, multimillonario de origen cubano y dueño de Venevisión, regenta un emporio mediático: la Organización Diego Cisneros. Posee setenta sucursales en treinta y nueve países" ${ }^{\prime \prime}$ Cisneros es amigo de George Bush padre: juegan juntos al golf y en 2001, el ex presidente de los Estados Unidos pasó las fiestas de año nuevo en la propiedad venezolana de Cisneros. Ambos están compitiendo por la privatización de PDVSA ${ }^{12}$. Otto Reich, subsecretario de estado para atender asuntos interamericanos, admite haber hablado con Cisneros esa noche ${ }^{13}$.

A las cuatro de la mañana del 12 de abril, para evitar un baño de sangre, Chávez dejó que lo arrestaran y se lo llevaran a la isla distante de Orchila. Sin presentar ningún documento firmado por Chávez para confirmar la noticia, los medios corearon su "renuncia". El mandamás, Carmona, se autoproclamó presidente y disolvió todos los cuerpos constitucionales, democráticos y legítimos del país. Venezolana de Televisión, el único medio de comunicación que disponía el gobierno, fue la primera emisora forzada a salir del aire cuando Carmona tomó el poder ${ }^{1+}$.

De cómo la prensa del odio incitó el golpe de estado contra Chóvez 


\section{Listos para el golpe}

La prensa saludó el golpe (aunque censuraron cualquier uso de dicha palabra) con un entusiasmo desfachatado. $Y$ con buenas razones. Al entrevistar al Almirante Carlos Molina Tamayo y Víctor Manuel García, director del instituto de estadísticas Ceca, a las 6.45 de la mañana, el presentador Napoleón Bravo se jactó de haber prestado su casa para grabar el llamado a la rebelión que hizo el General González González. García se refirió al papel que jugó en el centro de operaciones de los militares disidentes de Fuerte Tiuna: “Teníamos pocas instalaciones de comunicaciones, y yo tengo que agradecer a la prensa por su solidaridad y cooperación para ayudarnos a establecer comunicaciones con el mundo exterior y transmitir las instrucciones que el General González González me dio"

"Un paso adelante", fue el encabezado triunfal de El Universal. El periodista Rafael Poleo, quien completó la primera reunión de los líderes rebeldes, asumió la responsabilidad, junto a otros, para alistar los documentos del nuevo gobierno. Durante la tarde, el "Presidente" Carmona le ofreció a la hija de Poleo, Patgricia, el puesto de jefa de la oficina central de información. El decreto que establecía una dictadura fue respaldado por las patronales, la iglesia y los representantes de una falsa "sociedad civil", y también por Miguel Ángel Rodríguez, en representación de la prensa. Daniel Romero, secretario privado del ex presidente socialdemócrata, Carlos Andrés Pérez, y empleado del Grupo Cisneros, leyó el texto.

El ansia de venganza produjo la represión. El ministro del interior, Ramón Rodríguez Chacín, y un miembro del parlamento, Tarek William Saab, fueron arrestados, y luego expuestos a una multitud que los vituperó y maltrató. La RCTV disparó una cacería humana, al publicar una lista de las personas más buscadas y transmitieron en vivo las violentas búsquedas, imitando el ritmo agitado de los noticieros televisivos estadounidenses. La transmisión en vivo en todos los canales de la conferencia de prensa del Fiscal General Isaías Rodríguez fue quitada del aire súbitamente, tan sólo cinco minutos después de hablar de los excesos del "gobierno provisional" y de condenar el "golpe".

El 13 de abril, los partidarios de Chávez fueron liberados y los oficiales leales retomaron el control de la situación. Pero la única forma en que los venezolanos podían informarse de lo que estaba suce- 
diendo era a través de las transmisiones en español de CNN - transmitidas exclusivamente por cable-, o en las páginas de Internet del periódico madrileño El País y de la $\mathrm{BBC}$ de Londres. Al anunciar la rebelión de la $42^{\text {a }}$ División de Paracaidistas en Maracay, la CNN expresó su asombro por el hecho de que la prensa local no estaba diciendo nada. La libertad de información por la que tanto se había clamado fue sustituida por el silencio. Las pantallas se llenaron con películas de acción, programas de cocina, dibujos animados y juegos de béisbol de las grandes ligas estadounidenses, interrumpidas tan sólo con repeticiones del anuncio del General Lucas Rincón sobre la "renuncia" de Chávez.

Millares de personas se volcaron a la Internet y encendieron sus teléfonos celulares, pero solamente la prensa alternativa pudo sobreponerse a la censura. Los periódicos, la radio y la televisión populares comenzaron su vida en las barriadas pobres y se constituyeron en una fuente importante de comunicación y de información. Con su escasa experiencia, estos medios fueron los primeros blancos de la "transición democrática”. Según Thierry Deronne, presentador de Teletambores, Chávez nunca les pidió que transmitieran sus discursos.

Pero, mucho después del golpe, las fuerzas contrarias a Chávez no vacilaron en arrestar a los equipos editoriales y en requisar el equipo de esos medios, para garantizar que la única manera en que la gente pudiera enterarse de lo que estaba sucediendo fuera a través de la prensa de oposición. En Caracas, Radio Perola, TV Caricuao, Radio Catia Libre y Catia TV fueron objeto de cateo y su personal fue violentado y detenido.

Al final de la tarde del 13 de abril, una multitud se concentró en frente de RCTV (y más tarde, frente a Venevisión, Globovisión, Televen y CMT, así como a las oficinas de El Universal y El Nacional), tirando piedras y obligando a los periodistas a transmitir un mensaje en el que llamaban a la restauración de "su" presidente. Fue un ataque intolerable en contra de la prensa: los periodistas, atemorizados, transmitieron una petición de ayuda al aire, olvidando, convenientemente, que deberían estar del lado rebelde. "También somos parte del pueblo; también somos venezolanos y estamos haciendo nuestro trabajo. No es posible que los partidarios del Teniente Coronel Hugo Chávez [omitieron decir que era el jefe de estado] nos consideren como sus enemigos".

De cómo la prenso del odio incitó el golpe de estado contro Chávez 
Veinte horas antes de que el canal estatal Venczolana de Televisión volviera al aire, gracias a la ayuda de veinte integrantes de la prensa comunitaria y de soldados de la guardia presidencial. Salvo el caso de Últimas Noticias, ningún periódico salió al día siguiente para anunciar el regreso del presidente. Los canales de televisión privada no transmitieron comunicado alguno. Globovisión se limitó a retransmitir la información que ya habían difundido las agencias internacionales ${ }^{15}$.

Pese a que la restauración de la normalidad democrática no devino en represión contra la prensa, los medios siguen haciéndose las víctimas. Les dan prioridad a los "héroes del golpe", hablan de un "vacío de poder" y hacen llamados para que Chávez - a quien tildan de "asesino"- renuncie. Esos medios, llamados abiertamente "la prensa del odio", reivindican ser "la prensa del golpe".

NomAs

1. Ver www.analitica.com

2. Guzmán justificó haberlo hecho para demostrar cuán poco confiable era la prensa venezolana.

3. "Entrelíneas", El Nacional, 15 de marzo de 2002.

4. Nota del traductor: Esta cita puede consultarse textualmente en la nota editorial "Silbando en la oscuridad", publicada en Tal Cual, el 22 de marzo (http:// www.talcualdigital.com/ediciones/2002/03/22/[-tal.asp).

5. Programa Venezolano de Educación-Acción en derechos humanos.

6. Se descubrió más tarde que esa era el pscudónimo de un personaje anodino llamado Rafacl Kries.

7. Ver "Venezucla: a coup countered", en la cdición en lengua inglesa de Le Monde Diplomatique, correspondiente a mayo de 2002.

8. "Derroquen al gobierno", El Universal, 20 de marzo de 2002.

9. En español en el original. (N. del T.)

10. Ver la edición en inglés de Le Monde Diplomatique, marzo de 2002, así como las fotografías puestas en nuestro sitio de Internet.

11. Incluyendo a Univisión (que tiene el $80 \%$ de transmisiones en español en los Estados Unidos), Canal 13, Chilevisión, DirectTV Latin America, Galavisión, Playboy TV Latin America, Playboy TV International, Uniseries, Vale TV, Via Digital y AOL Latin America.

12. El primero quisiera verlo en las manos de una compañía estadounidense cercana a sus intereses, mientras que el úntimo le ha puesto el ojo a Citgo, la subsidiaria estadounidense de PDVSA.

13. Newsweek, París, 22 de abril de 2002.

14. Lo mismo ocurrió con Radio Nacional de Venezuela y con la agencia de prensa gubernamental Venpres.

15. Algunos periodistas renunciaron en señal de repudio, como André Izarra, de RCTV, en donde la administración ha censurado cualquier cobertura favorable a Chávez. 